\title{
Interactive Knowledge Co-Production and Integration for Healthy Urban Development
}

\author{
Rehana Shrestha $^{1, *}$, Heike Köckler $^{2}$, Johannes Flacke ${ }^{1}$ (D), Javier Martinez ${ }^{1}$ (i) and \\ Martin van Maarseveen ${ }^{1}$ \\ 1 Faculty of Geo-information Science and Earth Observation (ITC), University of Twente, PO Box 217, \\ 7500 AE Enschede, The Netherlands; j.flacke@utwente.nl (J.F.); j.martinez@utwente.nl (J.M.); \\ m.f.a.m.vanmaarseveen@utwente.nl (M.v.M.) \\ 2 Department of Community Health, Hochshule für Gesundheit, University of Applied Sciences (hsg); \\ Gesundheitscampus 6-8, 44801 Bochum, Germany; heike.koeckler@hs-gesundheit.de \\ * Correspondence: r.shrestha-2@utwente.nl; Tel.: +31-(0)53-487-4532; Fax: +31-(0)53-487-4575
}

Received: 14 September 2017; Accepted: 23 October 2017; Published: 26 October 2017

\begin{abstract}
The transformation of cities towards healthy urban living environments for all is a challenge that needs to be addressed through collaboration of all relevant sectors in a transdisciplinary research processes. This paper reports on the design and showcase implementation of a methodological approach, named Interactive Spatial Understanding Support System (ISUSS), that is intended to support interactive knowledge co-production and integration among practitioners and researcher in a specific local context. The approach involves the combined use of interactive maps on a MapTable and a rich picture. The goal is to stimulate, articulate and map stakeholders' knowledge on environmental health issues to come to a shared problem understanding. Drawing on the rich seam of data gathered over the reflexive engagement with the participants in Dortmund, Germany, we explored incidences of a transdisciplinary process. Findings suggest that the approach has the potential to encourage communication and social learning geared towards a shared understanding of the holistic problem situation. Whilst locally embedded spatial knowledge was shared using interactive maps on the MapTable, the rich picture elicited issues linked to wider geographical scale as well as non-spatial drivers. The paper concludes discussing research needs to further explore the approach among various other groups, including citizens.
\end{abstract}

Keywords: interactive maps; MapTable; rich picture; Interactive Spatial Understanding Support System; spatial knowledge; environmental health; transdisciplinarity

\section{Introduction}

The transformation of cities towards healthy urban living environments for all has received considerable attention in many international initiatives, such as the Ottawa Charter of the WHO [1], European Healthy Cities Movement [2] and the Health in All Policies Strategy [3,4]. Recognizing that urban planning processes fundamentally affect human health by influencing environmental determinants of health, scholars are now studying to integrate health promotion into urban planning at the local level [5-8]. Environmental health herein comprises those aspects of human health that are determined or influenced by factors in the environment including both physical and social determinants of health $[9,10]$ in a specific local context, e.g., at the place of residence. Considering the multifactorial aspects of environmental health, there is consensus that this subject is not structured within traditional disciplinary or sectoral boundaries. Owing to the strong linkages of environmental health issues to broader sectors in societies such as public health, social and private sectors, housing etc., researchers have endorsed collaboration by involving stakeholders from all relevant disciplines 
and sectors [11,12]. This understanding has brought attention to transdisciplinary research processes in the field of environmental health [13-15].

Transdisciplinarity implies knowledge production which is based not only on the integration of knowledge from different disciplines, but also on the inclusion of values, knowledge, know-how and expertise from non-academics [16-18]. As such, scientists and practitioners need to work on equal footing both taking co-leadership and requiring knowledge production and integration to be a collaboration and reciprocity among and between three main agents: (a) a legitimized decision-makers from practice; (b) researcher from a university or public science institution; and (c) those concerned with or affected by the problem addressed or by the decision made by the legitimized decision make [19] (p. 85). Nevertheless, involving such a diverse group of stakeholders entails that people may have different values as well as interpretations of the problem itself, not only on the solution. Multi-stakeholder knowledge, interests, and understandings are confronted with each other and are to be integrated into a shared understanding. Therefore, Scholz [16] (p. 5) formulates consensus building during the problem definition phase as one goal of transdisciplinary research. This is relevant in environmental health as health and health related problems are commonly understood in different ways by different people. The comprehensive understanding of health in the sense of the Ottawa Charter [1] goes beyond the absence of illness and medical treatment and follows setting oriented strategies of prevention and health promotion. A setting oriented approach seeks to include lifeworld oriented views of health. Activities to follow health promotion and prevention are confronted with "siloed" problem-solving attempts among organizations and professions. The challenge in environmental health may not be the disagreement about how to address a given situation but what the issues to be solved are [11]. Furthermore, overall knowledge on determinants of health has to be transferred into locally specific contexts.

Transdisciplinarity is not an automated process that arises by bringing together people from different disciplines or professions [20]. To encourage transdisciplinarity, it requires an ingredient that has been referred to as "transcendence" [20]. This implies giving up sovereignty over knowledge, minimizing power differences among researchers and practitioners, generating new insights and knowledge by collaboration, developing capacities to jointly consider the know-how of professionals and therefore enabling all participants to become co-creators of knowledge [20,21]. Thus, in transdisciplinary research, science is understood as a "public good that serves all stakeholder groups" equally $[16,18]$. Collectively, transdisciplinary processes need to stimulate mutual and joint learning between science and society in order to enable a shared understanding of a subject [22].

The motivation and justification to mobilize stakeholders into a process of joint and mutual learning through co-production and integration of knowledge have called for innovative approaches to transdisciplinary research. In general, these approaches need to encourage an open dialogue between participants in order to incorporate diverse perspectives and knowledge into the research process. Increasing research on health disparities and variation across geographic units advocates that health has a clear spatial connotation [23-25], particularly the relationships between the built environment, contextual factors on neighborhood level and health outcomes [12,26]. This calls for an integration of the spatial dimension in the transdisciplinary dialogue to incorporate locally spatialized knowledge into health-related planning processes. Consistent with such recognition, we contend that a methodological approach to facilitate the co-production of knowledge by integrating knowledge and perspectives of various professionals with explicit spatial connotation can provide a useful tool for mutual and joint learning processes. For this we advocate a multi-method approach we named Interactive Spatial Understanding Support System (ISUSS), which is applicable in transdisciplinary research, following the goals of transdisciplinarity being capacity building between science and practice as well as consensus building [16]. We assume that the ISUSS approach enables knowledge co-production and integration by involving stakeholders from different sectors and that it encourages interaction, social learning and shared understanding on the locally specific problem situation. 
In this paper, we provide the theoretical and conceptual basis of the ISUSS approach followed by a showcase implementation of the approach in the field of healthy urban development. The article pursues the following research questions: (1) How can knowledge co-production and integration among practitioners and researcher be supported by means of the ISUSS approach? (2) What insights are obtained with respect to interaction, social learning and shared understanding during the showcase implementation of the ISUSS approach in an environmental health context in Dortmund, Germany? (3) How does the ISUSS approach support a transdisciplinary research process?

Accordingly, the paper is structured as follows: In Section 2, we describe the theoretical basis of knowledge co-production and integration model and methods. Section 3 describes the conceptual framework of the ISUSS approach. Section 4 explains the implementation of the ISUSS approach in a workshop in the city of Dortmund. Section 5 reports and discusses the findings gained during the showcase implementation. Finally, we reflect on the approach to facilitate a transdisciplinary dialogue, including its strengths and limitations.

\section{Knowledge Co-Production and Integration in an Environmental Health Context}

Knowledge co-production and integration implies a process where knowledge is produced and used through interaction among people with different perspectives and background through cooperative endeavors and mutual learning [27]. Various approaches have been used in participatory research to involve stakeholders in the process of knowledge co-production, such as World-Café, Delphi discussion, forecasting, backcasting [28]. Similarly, various tools and methods are proposed for eliciting and capturing knowledge and perspectives such as sketch mapping, mental modeling, web-based mapping, mind mapping, photo mapping, interactive mapping [29-31]. In situations where problems need to be explicated holistically at an early stage by incorporating multiple perspectives of the stakeholders related to a wider social, political, cultural context, problem structuring research provides various approaches and methods such as rich picture in Soft System Methodology (SSM) and cognitive mapping in Strategic Option Development and Analysis (SODA) [32]. Likewise, with regards to knowledge integration, five types of integration are discussed in transdisciplinary research practice. These are interdisciplinarity integration, integrated system analysis, integrating different modes of thought, integrating interests and worldviews from different stakeholders, and integration relating to different cultures [33]. To facilitate these types of knowledge integration in transdisciplinary processes, several methods and methodology have been presented for representation, evaluation and transition of real world cases [34,35].

Different concepts of knowledge have been advocated by various scholars [36-38]. Knowledge co-production and integration in this study considers two dimensions of knowledge: explicit knowledge, which is formal and codable such as data and indicators; and tacit knowledge, which is personal, experiential, sectoral, and rooted in individuals' actions, experience, ideas, values, beliefs, and emotions. Confronting and combining tacit and explicit knowledge helps to make the explicit knowledge understandable for the stakeholders and increases the relevance of tacit knowledge in planning and decision making [39]. To link tacit and explicit knowledge, Nonaka and Takeuchi [40] have proposed a "spiral" model of knowledge creation (SECI model). Describing knowledge co-production and integration as a learning and social process, the authors suggest that knowledge can be elicited and shared interactively through four key modes: socialization (tacit with tacit), externalization (tacit with explicit), combination (explicit with explicit), and internalization (explicit with tacit).

Recognizing that most real world problems are complex and need to be addressed in its complexity rather than in parts, scholars have argued for the combined use of two or more methods within a single intervention known as "multi-method" or "multi-methodology" [41,42]. Although a prescribed "best way of combining methods is unlikely to exist", Franco and Lord [42] advocate that choice of methods also depends on the nature of the task to be supported. Environmental health is being recognized as such complex, multi-dimensional problem that need to be understood holistically by incorporating 
knowledge and perspectives from various stakeholders. Additionally, determinants of environmental health are found to have a strong spatial connotation at the local scale and are influenced by various regional and supra-regional drivers [43]. In this regard, a multi-method approach is pertinent in the context of environmental health. Thus, a multi-method that deems appropriate in our approach is the combination of interactive maps to depict the spatial dimension of stakeholders' knowledge on environmental health at the local scale and a rich picture to depict knowledge and perspectives of stakeholders that may cover wider geographic scale and include spatial as well as non-spatial factors.

Interactive maps, are understood as dynamic maps supported by interactive interfaces. Owing to its dynamic features, interactive maps permit the users to browse, navigate, retrieve, filter large amount of spatial information in a gradual manner and in the same time support sketching as the users' goals are continually reformulated. Therefore, interactive maps can be effective organizers of geospatial data and can facilitate the exploration of problems and solutions in geographic space, support the integration of spatial information during reasoning, deliberation and communication among stakeholders [44].

A rich picture, is a graphical, "cartoon-like" representation of a problem situation that is particularly used during early phases to record stakeholders' perspective and knowledge of a situation. Using roughly sketched symbols such as stick figures with short text rather than a linear prose structured in long text, a rich picture provides a strong visual expression about features of interest and the interactions among those features [45]. It allows individuals to communicate their story of the relevant conditions affecting a situation and act as a tool for conversation and learning [32]. Therefore, the rich picture can be a strong tool to incorporate knowledge and perspectives from various stakeholders in the same picture when used in participatory setting.

\section{Conceptual Framework of the ISUSS Approach}

Figure 1 presents the conceptual framework of the ISUSS approach and its interrelation with the SECI model and SSM. The intended outcome of the ISUSS approach is to enable communication and social learning throughout a process and to develop a shared understanding about the problem situation in a specific local context. The framework acts as a platform to enable integration of explicit knowledge and stakeholders' tacit knowledge during a collaborative stakeholder workshop. The ramework distinguishes three phases: preparation, process and intended outcome. The preparation phase includes setting up the spatial data and determining facilitation interventions. The process phase is divided into iterative steps that the stakeholders are asked to carry out. Whilst the stakeholders are engaged in these steps, they follow the cyclical process of the SECI model implicitly (top horizontal). In doing so, the stakeholders move from a situation where they view the problem from their own frames to a situation where they share their views to others, following the first two stages of SSM (bottom horizontal). Each of the steps in the process framework is supported by either interactive maps or rich picture. 


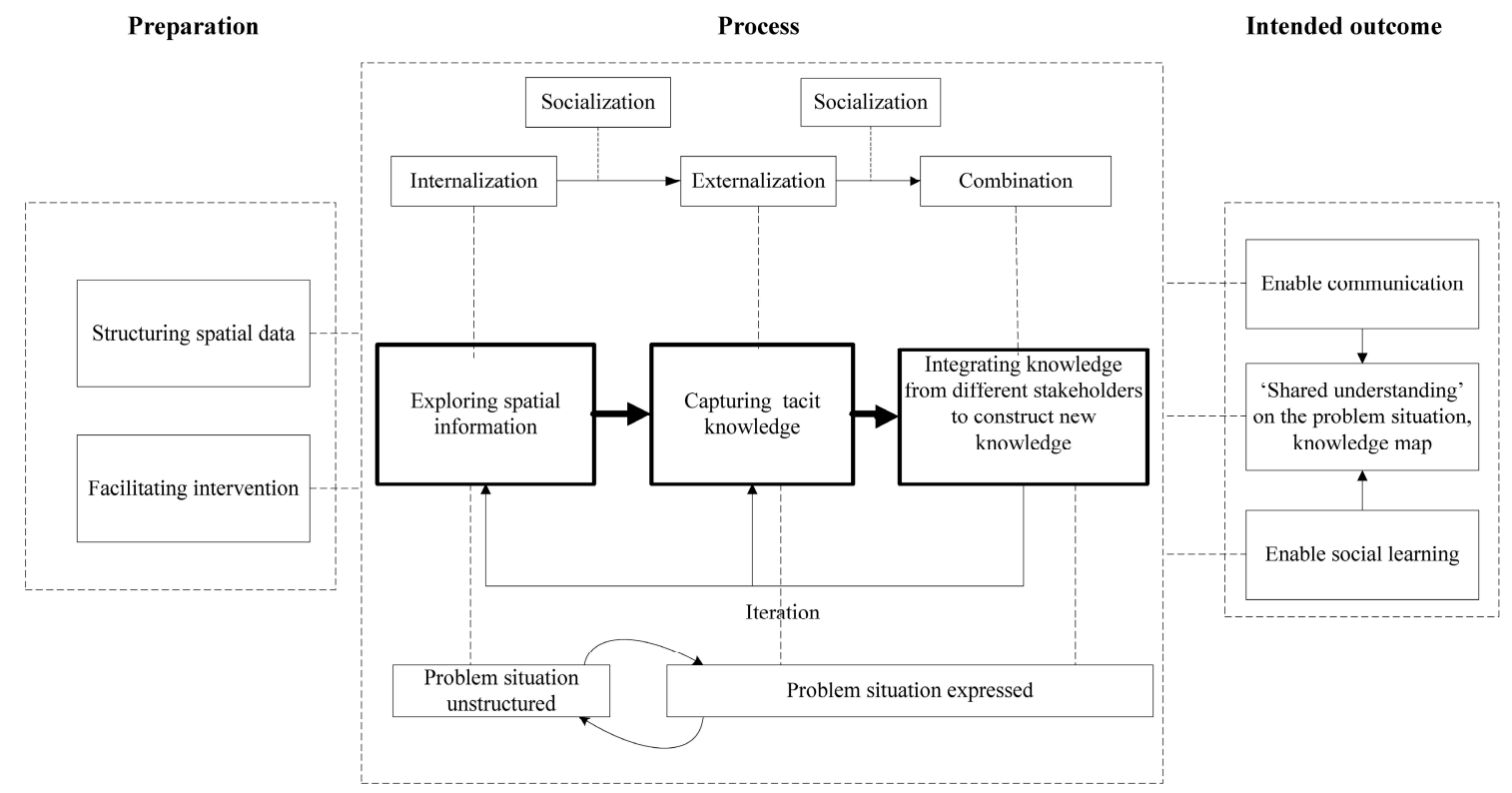

Figure 1. Conceptual framework of the Interactive Spatial Understanding Support System (ISUSS) approach.

\subsection{Preparation Phase}

\subsubsection{Structuring Spatial Data}

Structuring spatial data entails organizing spatial data in such a way that it provides relevant spatial information about the context under discussion. Essentially this means, collecting, processing, arranging and visualizing spatial information in the form of meaningful indicators at an appropriate scale and resolution to create maps ready for interactive use.

We use a MapTable- a horizontal table surface with a touch sensitive screen-in combination with Phoenix 1.1 software (at the time of the research, Phoenix 1.1 from Geodan was found best suited for our concept of the ISUSS. However, we customized some of the functionalities of the software to fit our purpose). The MapTable provides a platform for spatial discussion with a shared map interface to facilitate interaction among users and between users and the system through its touch-enabled interface during face-to-face group collaboration [46]. The table allows using GIS (Geographical Information System) functions for navigation, map structuring, and visualization as well as to produce and store spatial content interactively during the discussion. For the ISUSS approach, the following GIS functions are provided: map layer management and visualization, navigating tools, 3D visualization tool, multiple map overlaying, annotating, sketching and iconography.

\subsubsection{Facilitation of the Workshop}

The collaborative dialogue includes listening to each other, treating each other's interests with respect, looking for common interests rather than differences, and challenging assumptions [47] in [48]. In such a collaborative dialogue, group facilitation plays a critical role to ensure group performance and effectiveness. A facilitator can enable such a collaborative dialogue by ensuring that all participants feel comfortable to share their ideas and thoughts, to show empathy and critical judgment, and to analyze issues deeply. Furthermore, the participants need to be stimulated to think beyond their disciplinary boundaries as well as be willing to put their "half baked" ideas forward [47] (p. 46) in [48].

Hirokawa and Gouran [49] divide the activities of facilitators into three areas: substantive, i.e., related to topics discussed; procedural, i.e., drawing attention to process elements like the agenda; and relational, i.e., attending to social or emotional issues [50]. In the ISUSS approach, the facilitator stimulates the stakeholders to share their perspectives, asking them for clarifications 
by encouraging them to make spatial references of their claims on the same. Moreover, the facilitator asks guiding questions in each step of the process helping to sharpen the arguments and to focus the discussion. Additionally, the ISUSS approach also requires tool-related facilitation. The use of technology during a collaborative dialogue could be a barrier due to participant's anxiety to the technology, the system's inflexibility, low reliability and learning time needed for participants to use the technology [51]. Therefore, the facilitator, also known as chauffeur, ensures that the discussion is not hampered while using the interactive maps on the MapTable. Similarly, while using the rich picture, the facilitator ensures that each stakeholder is encouraged to draw and to explain what is drawn to the other participants.

\subsection{Process}

\subsubsection{Exploring Spatial Information}

The ISUSS process asks the stakeholders to explore and understand the spatial information provided in order to get insights into the context. While doing so, explicit knowledge is internalized into the individual's tacit knowledge bases in the form of mental models or technical know-how. Such effects have been observed by Te Brömmelstroet and Bertolini [38] in a planning context. Furthermore, when the stakeholders are engaged in exploring the information spatially, we assume that their tacit knowledge is triggered and they are encouraged to make it explicit. Thus, the ISUSS approach assists the discussion on a spatial context by providing interactive maps integrated into the MapTable. The stakeholders can explore the spatial information in the form of indicators individually or in combination, can compare them or evoke contrasts between various scales—such as neighborhood to citywide.

\subsubsection{Capturing Tacit Knowledge}

The second step allows the stakeholders to articulate their views, experiences, issues and concerns as a part of defining the problem situation. In doing so, they are presumed to undergo a process of externalization, i.e., articulating tacit knowledge. Several ways of expressing tacit knowledge have been acknowledged, for instance through metaphors, analogies, or models [39,52]. Individuals express their perspectives, experiences or stories which they tend to relate to certain geographical locations. When the individuals are facilitated to link those experiences explicitly with related geographic objects on maps it can improve the discussion on a spatial context [53,54]. Annotation and sketching tools help individuals to illustrate spatial relationships among objects of interest and to mark specific locations of issues that are retrievable and reviewable later [55]. Such sketching tools enable the stakeholders to make their understanding and their knowledge of the situation explicit while interacting with others.

\subsubsection{Integrating Knowledge from Different Stakeholders to Construct New Knowledge}

As part of expressing the problem situation in total, different knowledge from the stakeholders is combined collaboratively to construct a more holistic picture of the problematic situation. It includes systematizing, sorting, adding [52] and thus interrelating the issues and concerns of the stakeholders by applying the rich picture method.

\subsection{Intended Outcome}

\subsubsection{Communication}

Planning has become an argumentative process rather than purely instrumental and technocratic rationality [56]. Such an argumentative process allows to "appreciate different ways in which practitioners formulate and construct what the problem should practically be-before they can provide plausible alternatives or recommendations" [57] (p. 5). Communication is an important element in a transdisciplinary process to construct a shared understanding, for which acceptance of a degree of 
collaboration and reciprocity is needed [58]. This includes accepting the opinions of others and that truth and values are the outcomes of social interaction within specific contexts [48]. In the same line, Innes [59] argues that for a communicative and collaborative process to succeed, the process needs to encourage participants to address both explicit knowledge and tacit knowledge. In this line of reasoning, the ISUSS approach should encourage communication among the stakeholders.

\subsubsection{Social Learning}

Stimulating social learning among different stakeholders in a planning process is both an end and a means to achieve a better-informed outcome and shared understanding [48,59]. Social learning may occur through imitation and under the influence of norms and social context [60]. To encourage social learning, "a process must demonstrate that a change in understanding has taken place in the individuals involved, that this change goes beyond the individual and becomes situated within wider social units or communities of practice and occur through social interactions and processes between actors within a social network" [61] (p. 1).

To observe this change in understanding, a mental model has been advocated as a bridging concept [62]. A mental model is a "schemata of interpretation" [63] of external reality that people form in their minds to make sense of specific issues, to consider certain aspects of the problem more important, to select and highlight certain facets of the issues, and to promote a particular perspective of problem definition or interpretation [64,65]. Therefore, changing mental models with the support of social interaction is considered an indicator of social learning.

Mental models are determined to a great extent by the disciplinary background of the stakeholders in ways that reflect their training and techniques. Stakeholders may gain from making their frames more explicit and using them for generating different perceptions about the central issues [66]. Explicit mental models help to encourage an interdisciplinary communication, which may lead to forming a holistic understanding of the problem beyond the boundaries of single disciplines. Making mental models explicit, however, is not an easy task, since they tend to be rooted in the different rationalities of the stakeholders involved [67]: "from systematized accounts and analyses, and practical manuals, to stories exchanged in the flow of life, and skills exercised in doing practical work" [68]. As such, appropriate elicitation techniques are needed to explicate the mental model of each participant. In this regard, the ISUSS approach should support the stakeholders to articulate their frames on the problem situation as well as local context and communicate them to other stakeholders from different sectors in a common language shared by all.

\subsubsection{Shared Understanding}

Shared understanding refers to a degree of similarity between the mental models of the participants. The process of reaching a shared understanding has been viewed as an outcome of a social learning process where individuals interact with each other, take into account each other's perspectives, try to change their own mental models, negotiate and therefore identify common ground [69]. In doing so, the group members are engaged in "divergent" and "convergent" thinking processes and take into account different stakeholders and viewpoints to produce a representation that conveys a "shared social reality" [70].

While going through the ISUSS process phase, participants have the opportunity to engage in divergent thinking and share their knowledge, perspectives and initial interpretation of issues of concern on the locally specific problem situation. While engaging in convergent thinking, participants identify commonalities in views, learn about different issues and perspectives and therefore form a consolidated perspective of the issues. In doing so, in the ISUSS approach knowledge and perspectives at neighborhood scale are captured as spatial knowledge map and at a wider geographic scale in the rich picture. 


\section{Implementation of the ISUSS Approach in Dortmund, Germany}

\subsection{Context}

The ISUSS approach has been developed in the context of the junior research group Jufo-Salus "Cities as a healthy place to live, regardless of social inequality" [71]. The project started in 2013 with the aim on integrating the concepts of sustainability and health for planning in urban areas for two German municipalities, Dortmund and Munich. The main focus of the project is on addressing health inequalities in the urban area including both salutogenic and pathogenic factors of the environment and their unequal distribution across various socio-economic groups. The city considered in this study is Dortmund.

The city of Dortmund is located in the western part of Germany in the former coal mining and steel-producing, highly urbanized region of the Ruhr. Influenced by historical industrialization and more current deindustrialization processes, the city is undergoing a long-lasting economic transformation, resulting in high unemployment rates compared to German averages. The highly fragmented city shows large socio-economic disparities with significant differences in environmental quality. The persistent spatial inequalities in relation to unequal distribution of environmental burdens (air pollution and noise pollution) and benefits (green areas and forest areas) in the city of Dortmund have been highlighted in recent research [72]. In addition to strong social and ethnic segregation in Dortmund, the city is characterized by a spatial structure with better-off neighborhoods in the south and disadvantaged neighborhoods in the north which is typical for the Ruhr [73]. Moreover, the city reveals significant differences in health outcomes. The average life expectancy in 2011 ranges from 66.3 years in the Nordstadt district in the north to 76.3 years in a southern district of Dortmund [74].

One central element of the Jufo-Salus project is a transdisciplinary dialogue amongst scientists from urban planning and public health as well as practitioners from relevant fields with regard to environmental health. In this dialogue neither citizens nor politicians have been actively involved. For the transdisciplinary dialogue, other than the ISUSS approach, different methods, e.g., World-Café and planning game have been applied. [75]. The whole research process of the Jufo-Salus was structured around stakeholder workshops, directing the focus of the content on mixed land use and migration. This has influenced the preparation phase of the ISUSS workshop described below with respect to the selection of stakeholders, indicators and the study area of Nordstadt.

The ISUSS approach was first tested in a number of workshops with the researchers in the Jufo-Salus project, MSc students and academics from the TU Dortmund University. All participants were familiar with environmental health issues in Dortmund and had various disciplinary backgrounds, such as spatial planning, public health, transport planning. Based on the feedback from the participants and our observations from these test workshops, we refined the ISUSS approach with regard to the structuring of spatial data, facilitation intervention and workshop design. The ISUSS workshop itself was one three-hour stakeholders' session. The workshop took place on 26 October 2014 in Nordstadt in the office of a local NGO named Borsig 11 e.V. It was conducted in German language.

\subsection{Stakeholder Selection}

The selection process of stakeholder was focused on involving practitioners representing different sectors and interests. In this regards, they were selected based on their professional roles, expertise and knowledge on environmental health issues in Dortmund. Potential participants were identified based on the contacts from prior workshops in Jufo-Salus. A total of six individuals participated in the workshop session. Participants included two municipal staffs from health and urban planning departments respectively and three practitioners having a background as NGO/social entrepreneur in neighborhood association, childcare and Local Agenda 21 respectively. The second author acted as a participant from research. All the participants were closely related to the Nordstadt. Two authors of this paper facilitated the workshop, the first author carried out the role of a chauffeur, and the third author provided facilitation. One person observed the whole workshop. 


\subsection{Workshop Design}

Figure 2 provides the timeline for the workshop session, which was divided into three main steps. Spatial data used in the workshop were provided by the city of Dortmund (Table A1 provided in Appendix A). Indicator maps were prepared based on the issues discussed during earlier workshops and as requested by the participants during the test workshops. Data were provided at the smallest scale available.

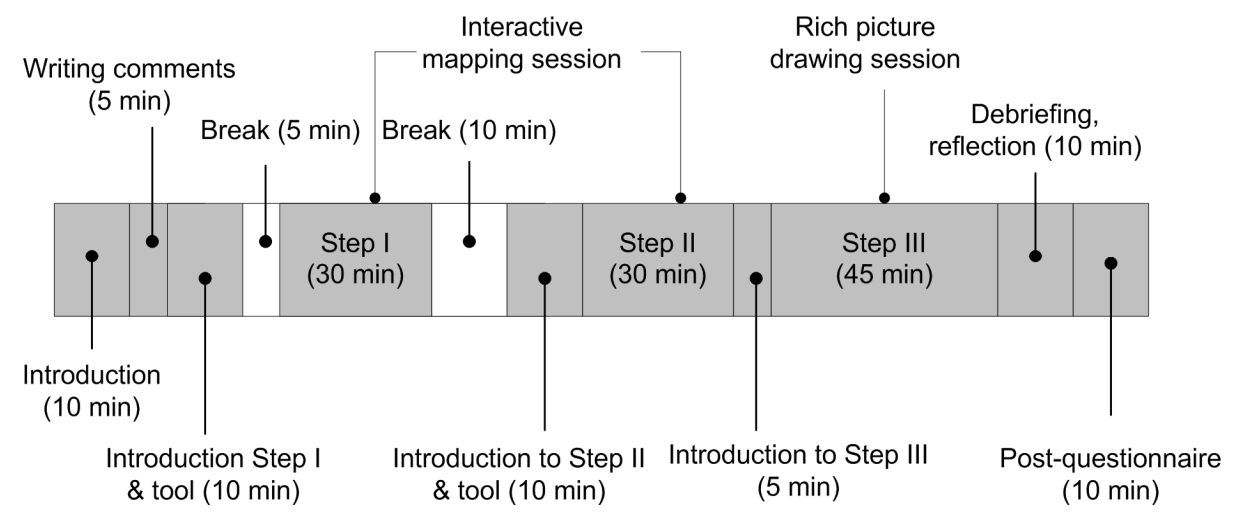

Figure 2. Timeline for the workshop session.

The session began with an introduction to the objective of the workshop and to the study area. Next, the individual participants' perceptions of the most important issues in the case study area with respect to environmental health were collected. A short explanation of the steps and relevant tools was provided. At the end of the session, each participant was asked to reflect on the issues collected at the beginning, their experiences with the ISUSS approach and to complete an evaluation questionnaire.

The interactive mapping session was carried out using interactive maps integrated into the MapTable (Figure 3a,b). This session was divided into two steps as reflected in Figure 2-exploring spatial information (Step I) and capturing tacit knowledge (Step II). The purpose of the first step was to explore spatial information about the area and to evoke the initial concerns of the participants. To do so each participant was encouraged to choose spatial indicators on the MapTable that he/she perceived to be important and to explore the case study area with respect to these. The second step included eliciting and sharing each other's knowledge on environmental health issues relevant to the case study area and add their tacit knowledge on the MapTable. The initial framing question was focused on resources, opportunities or the lack thereof in terms of environmental and social factors.

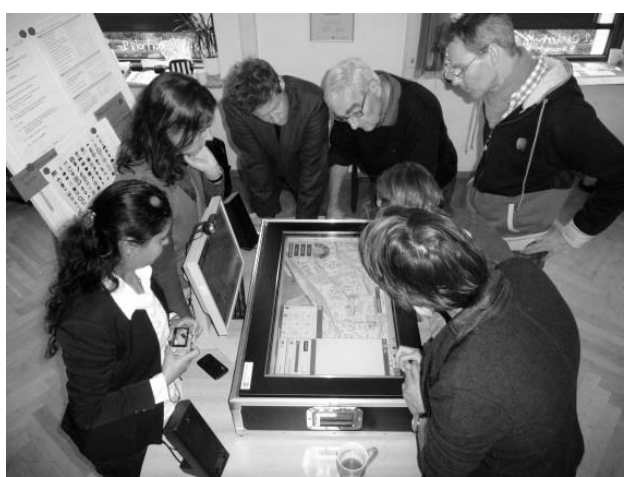

(a)

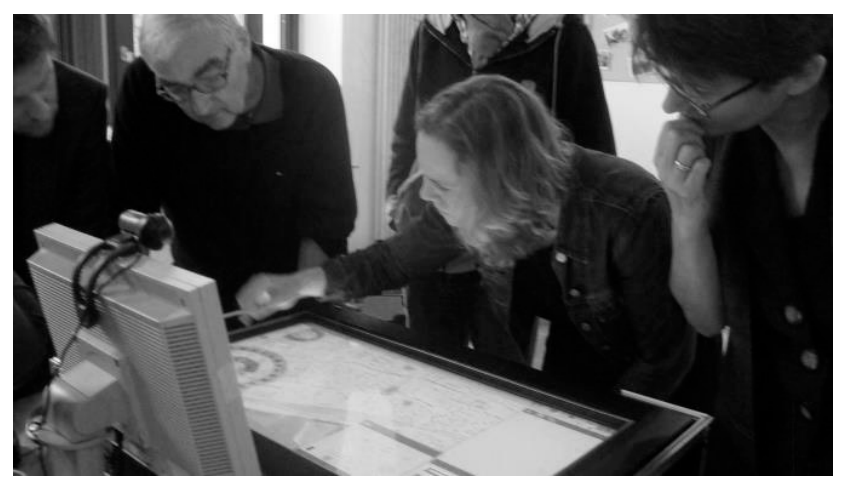

(b)

Figure 3. (a,b) Stakeholders working with the MapTable. 
Figure 4 shows the participant drawing a rich picture in Step III of the process. The aim of this step was to form a holistic view on the problem situation by integrating concerns and knowledge from each stakeholder. The participants were asked to make a pictorial representation of the most important issues relevant to environmental health, to show how they are interrelated to each other and to identify vulnerable groups to issues perceived as problematic in relation to environmental health.

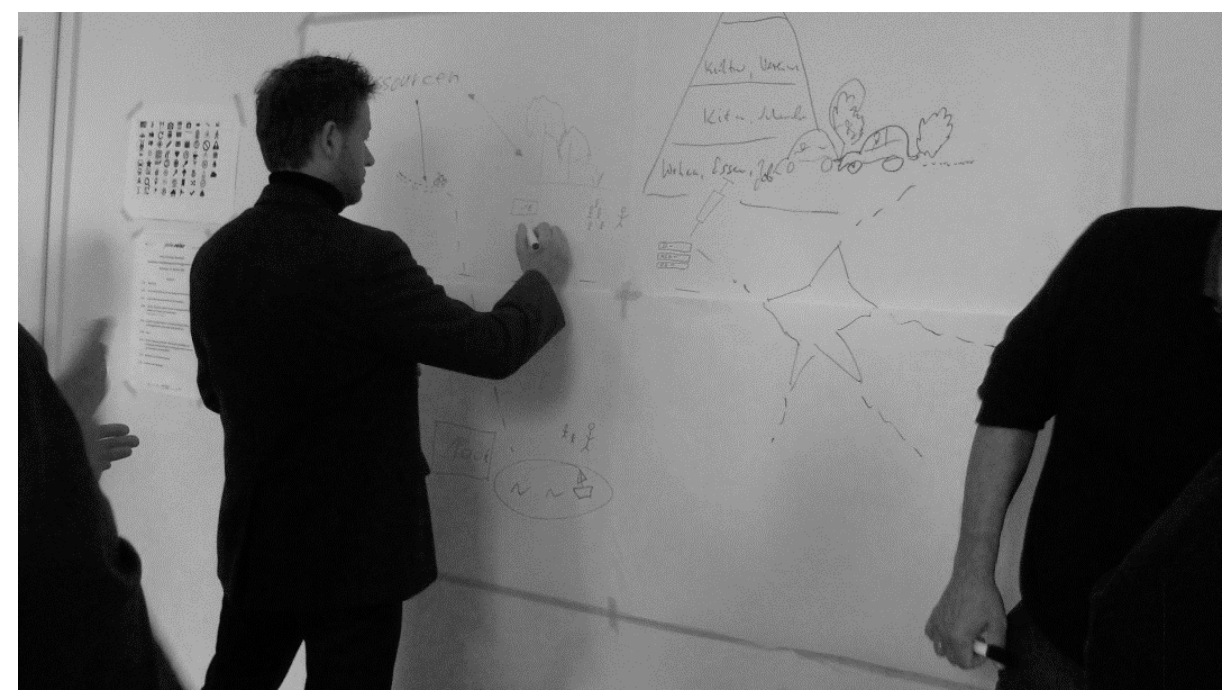

Figure 4. Stakeholders drawing the rich picture.

\subsection{Workshop Analysis}

Data for analyzing the workshop were collected using seven sources, namely screen capture of the interactive mapping session, voice recording, observer's notes, short debriefing on the overall workshop approach by each participant immediately after the session, a post-session questionnaire, the knowledge map produced on the MapTable and the rich picture. The screen capture and voice recording of the workshop and debriefing session were intended to capture complex interactions between the participants, the participants and the facilitators, and the participants and the tools. After the workshop, the recordings were transcribed and translated in English with time coding and were used to augment the questionnaire and observational results with illustrative examples of the participants' interactions and responses. The post-session questionnaire consisted of two parts: the first part on the usefulness of the interactive maps and the second part on the usefulness of the ISUSS approach to achieve the intended outcomes-communication, social learning and shared understanding. Participants were asked to use five-point Likert scales to express their level of agreement and provide a short answer on each question. The observer's notes were used to consolidate the findings from the workshop transcript and participants responses.

The analysis of the workshop was based on the reflexive engagement of three of the authors with the stakeholders from Dortmund during the workshop session. Reflexive engagement means "making visible, paying attention to, negotiating and discovering at the various arenas" [76] (p. 90). The adoption of this approach was motivated by the objective to understand the subjective meaning participants attributed to their experience using the ISUSS approach. The evidences were gathered and categorized by the first author, and were then re-examined by the second and the third author independently.

\section{Insights from the ISUSS Workshop}

Throughout the entire ISUSS workshop all six participants were engaged in exploring data, mapping issues, discussing their own perspectives and knowledge in relation to environmental health in the case study area and later elaborating it into a pictorial form. One participant from urban planning was active immediately after introducing the methods whereas others required to 
be facilitated more, particularly in using the tools on the MapTable. The participants studied the indicators either individually or in combination and made use of 3D visualization when needed especially to identify specific locations. More stimulation and tool support was needed during the second step when they needed to sketch and annotate on the MapTable to explicate their knowledge. Drawing the rich picture needed initial activation before the participants drew actively. In general, the ratings given by the participants on the usefulness of interactive maps ranges between very useful to moderately useful (Table 1, Questions 1-2). The ratings on the usefulness of the ISUSS approach to achieve the intended outcome also ranges between very useful to moderately useful except for one participants who gave lower responses for learning about new issues during the workshop (Table 1, Questions 3-6).

Table 1. Questions and participants' responses on the usefulness of method and ISUSS approach using five point Likert scale.

\begin{tabular}{|c|c|c|c|c|c|}
\hline & Very Useful & Useful & Moderately Useful & Not So Useful & Not Useful at All \\
\hline \multicolumn{6}{|c|}{$\begin{array}{l}\text { 1. To what extent is the MapTable useful for you to explore the data and understand the information in relation to environmental } \\
\text { health related spatial inequalities? }\end{array}$} \\
\hline Spatial information exploration & 3 & 0 & 3 & 0 & 0 \\
\hline Understand spatial inequalities & 4 & 0 & 2 & 0 & 0 \\
\hline \multicolumn{6}{|c|}{ 2. To what extent is the MapTable useful to elicit your own knowledge and shared them to others? } \\
\hline Own knowledge elicitation & 1 & 2 & 3 & 0 & 0 \\
\hline Share knowledge to others & 2 & 3 & 1 & 0 & 0 \\
\hline \multicolumn{6}{|c|}{ 3. To what extent is the workshop approach useful to communicate your points of view to others? } \\
\hline Communication & 3 & 2 & 1 & 0 & 0 \\
\hline \multicolumn{6}{|c|}{ 4. To what extent is the workshop approach useful to learn new aspects on the problem situation? } \\
\hline Learn new aspects & 0 & 4 & 1 & 0 & 1 \\
\hline \multicolumn{6}{|c|}{ 5. To what extent is the workshop approach useful to understand and learn about other participant's perceptions and concerns? } \\
\hline Learn about others' perspectives & 2 & 2 & 2 & 0 & 0 \\
\hline \multicolumn{6}{|c|}{ 6. To what extent is the workshop approach useful to find common among participants on the important issues? } \\
\hline Find common ground & 0 & 6 & 0 & 0 & 0 \\
\hline
\end{tabular}

Note: usefulness of rich picture was derived from participants' debrief, observation from facilitator and observer.

\subsection{Workshop Process: Enabling Active Stakeholder Participation}

The use of interactive maps on the MapTable acted as a platform for the participants to support the internalization process of the existing spatial information. The ratings given by the participants were corroborated by their comments on the questionnaire. Three participants referred to spatial visualization of indicators as particularly relevant to see the connection between the places they know and the respective spatial information as well as to visualize various driving factors together. In doing so, information and knowledge are communicated in an interactive and dynamic way, the dialogue becomes energetic, and content in the form of map layers and stakeholders' knowledge is shared easily, as observed also by Pelzer et al. [77]. The screen capture showed that user-friendly interfaces together with the possibility to zoom in, pan and overlay different layers supported the participants to explore the environmental and social indicators together in multiple combinations instantly. For instance, by combining the indicators "Share of children under 6 years" with "Noise level from the street", the participants were able to explore their concern regarding the share of children being exposed to high noise levels. Structuring data to visualize indicators at a disaggregate level and enabling comparison of the Nordstadt with the entire district and even across different districts of Dortmund was particularly relevant to understand spatial inequalities as stated by the participants while working on the MapTable. This supports the fact that spatial inequalities are a relative phenomenon rather than an absolute phenomenon and the existence of spatial inequalities in an area can only be ascertained after knowing what is going on in other parts of the city [78,79]. However, some tensions and resistances also surfaced, as one participant stated that the lack of small-scaled data at block level limited their analysis. 
In relation to the use of interactive maps to externalize and capture tacit knowledge, one participant stated as being a good platform to "trigger discussions". Referring to the spatial visualization of indicators, annotation and sketching functionality, one participant stated in the questionnaire that they were able to draw their "ideas and scenarios quickly and further discuss them with others". This resonates with Forester [80] acknowledging that when the sketch of a plan was used to mark the boundary of the topic to be discussed, it helped the participants to clarify what they meant, to share and sharpen their arguments and to focus the discussion. Supported with the sketching tools and by using different colors and icons, they added knowledge at the scale of neighborhood area, as shown in Figure 5.

The elaboration of the issues and concerns through the rich picture (Figure 6) supported the stakeholders in constructing an integrated picture of the environmental health situation in the study area. Furthermore, we observed the complementary use of the two methods. Visualizing spatial inequalities and communicating the views having localized spatial connotation was well supported by the interactive maps on the MapTable. For example, while discussing the topic of accessibility and transport safety, the participants used the interactive map to develop a bicycle route that connects Nordstadt to the city-wide cycling infrastructure. When the discussions incorporated the reference to wider geographical contexts and non-spatial knowledge of the participants, such as health insurances of non-German inhabitants or the rent index, the joint elaboration of discussion through a rich picture enabled the participants to articulate, share and thus integrate such non-spatial or yet to spatialize knowledge into the holistic view.

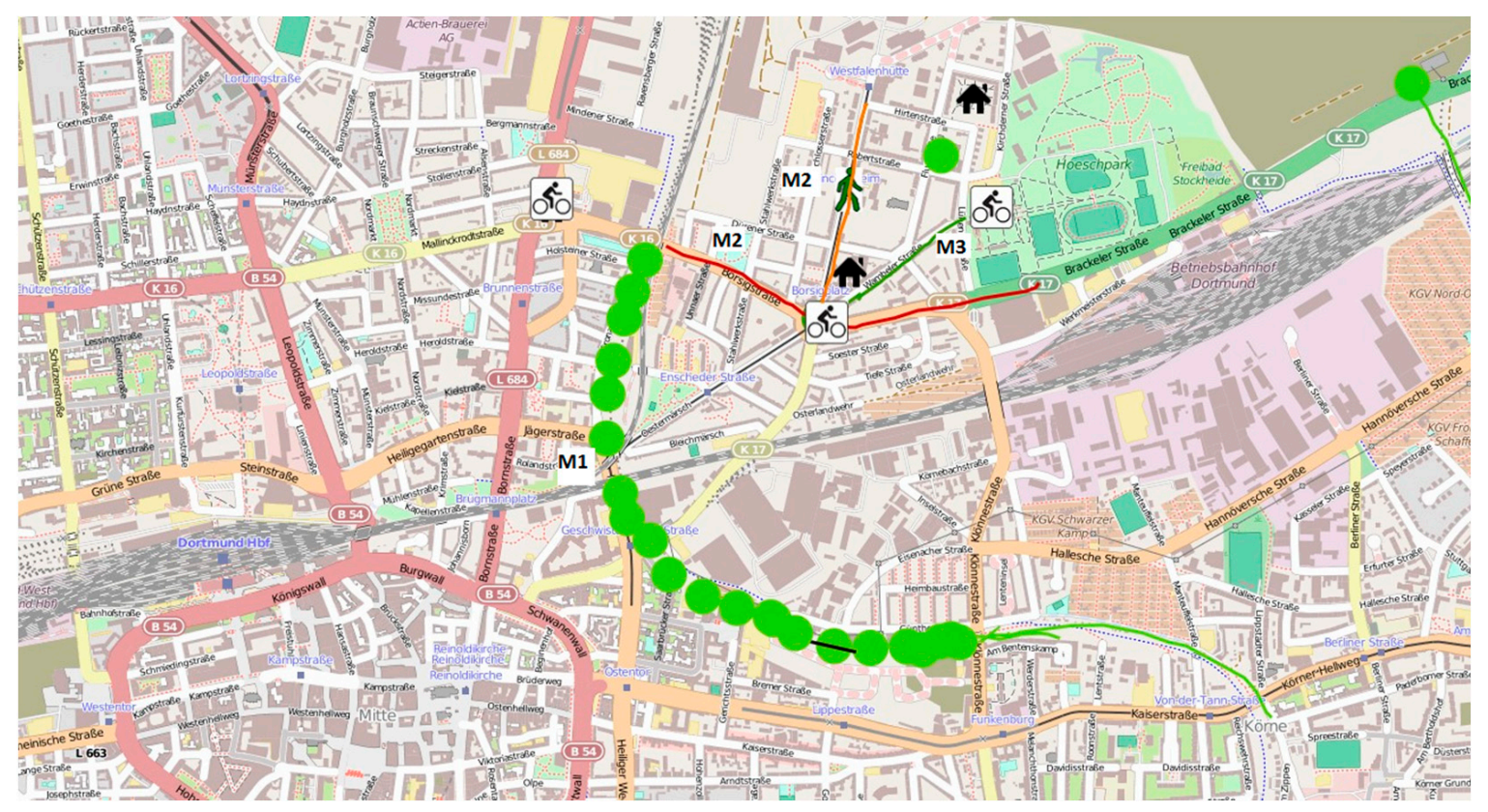

Figure 5. Spatial knowledge map: M1-inequality in accessibility and possibility to extend cycling routes between the northern and southern part of the city; M2-safety concerns; and M3-good accessibility to parks inside the Nordstadt. 


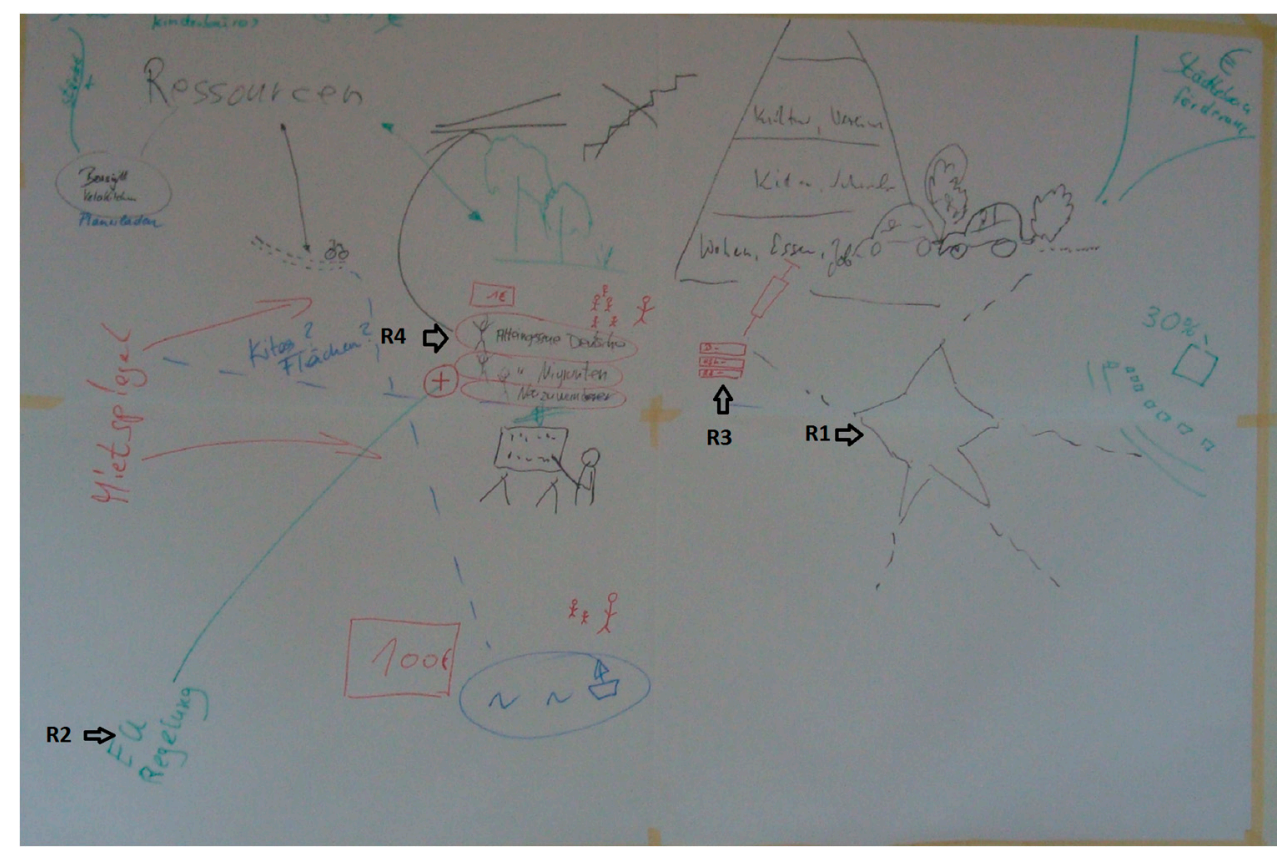

Figure 6. Rich picture: R1—the central square in Nordstadt being linked with different environmental burdens and benefits (e.g., cars causing pollution, green areas as resources); R2-local and supra-regional drivers such as EU directives, rent index, EU health insurance policy not being able to provide proper health insurance to non-German inhabitants coming from other EU-Countries; R3-vehicles coming from other cities for various and even illegal activities, including buying drugs; and R4-different vulnerable groups.

\subsection{Workshop Outcomes: Incidences of Transdisciplinary Aspects}

The ISUSS workshop conducted in Dortmund contained various outcomes that are characteristic for a transdisciplinary research process. Particularly the elements of communication and interactions among the participants and social learning were observed during several occasions throughout the workshop. As one workshop participant phrased it:

The system has produced discussions that wouldn't have taken place without it. In contrast to other workshops where presentations are using slides followed by the discussion, the approach was different as you stand in front of the screen [the MapTable] and you can really do something and discuss it.

By guiding the participants through a structured facilitation and enabling them to work actively with the interactive maps on the MapTable, the participants engaged with and questioned the existing spatial information. Additionally, the MapTable appeared to be a useful medium to bring the people together, encourage them to "show what they meant". This corroborates with findings from Hopkins et al. [81] who found increased interaction among groups working with horizontal compared to vertical displays. In the sense of a transdisciplinary approach, in which the participants are the active agents and co-creators of knowledge, the ISUSS approach appeared to support such process of co-creation by providing a "dialogue space" where evidence-based discussion is encouraged. This view was also reflected in the statements from two participants:

[ ... ] because you get together in a different setting [bring different knowledge] and talk about specific issues [that the individual perceive as important], it is something completely different compared to just presenting some statistics on a screen $[\ldots]$.

[... ] when you use the indicators shown in the maps for discussions in the city council, you discuss based on fact and not about what you believe. 
In this regard, the interactive maps allowed the participants to raise and register their views and further discuss them in more depth. Raising and registering views was also continued during the rich picture drawing session where the use of pictograms instead of texts and the linking of their views to others was stated by the participants as salient features to support communication. Whilst perceived improved communication is not different from the one claimed when the methods are deployed in isolation [82], it can be argued that the enhanced communication and enriched insights about the problem situation in the ISUSS approach was facilitated by the combined use of the interactive maps and the rich picture. This was clearly indicated in one participant's comment:

Concerning the topics of noise and air pollution it may be sufficient [showing them on the MapTable]. But I see another field, i.e., the field of health insurance. I had the feeling that in the beginning this doesn't fit into the map. But it is relevant when talking about city as a healthy living space. So, I mention it here at the end [showing the rich picture].

Successful communication leads to enriched insights and social learning. The interactive maps and the rich picture enabled the participants to convey their thoughts to others and as such social learning was evidenced at different points in the workshop. For example, the participants overlaid multiple environmental and social indicators (e.g., share of children under six years overlaid with noise level ( $\left.\mathrm{L}_{\mathrm{den}}\right)$ from streets) on the MapTable and discussed the same further, learning that children's routes to school are partly highly affected by noise and air pollution. The counterintuitive nature of the results from the interactive maps elicited the existing mental models of the participants. Through reasoning and interaction, the participants sought to change their existing knowledge. For instance, after observing a strikingly high share of unemployment aid recipients (SGB II) along a certain street (Brunnenstraße), the participants were forced to think in-depth and discussed potential underlying reasons for the same. In the same way, the participants realized that the situation according to $\mathrm{PM}_{10}$ concentration on a specific street (Brackeler Straße) is still problematic, but better than assumed. This street has been a symbol for high levels of air pollution in Dortmund and has been in the media quite often. One participant explained different initiatives being undertaken to improve the situation in that street. Learning was also ensured during the rich picture drawing session where the participants emphasized that by drawing a holistic view of the problem situation "linkages became obvious and complex relations were represented clearly". Nonetheless, one participant perceived less learning. He stated of being aware of the topics that were discussed and resonates with what Goodspeed [83] found that participants who attended planning workshops more frequently (self) report less learning.

Operationalizing and assessing the concept of shared understanding has been reported difficult as it includes individual cognitive processes that often remain implicit [69]. However, construction of shared meanings was evidenced during the workshop. For instance, while discussing the accessibility of green areas from residential areas, part of the discussion was on whether the focus should be in terms of time and distance or in terms of safety of the access route. Consensus was reached about assessing the quality of the access from a safety point of view. Likewise, improving accessibility to green areas was identified as important in the case study area to promote the health of people. In general, the participants also rated the approach being helpful to find common ground. Nonetheless, the presence of consensus in the group as acknowledged in observer's notes depict that participants' opinions were mainly confirmed.

\section{Discussion and Conclusions}

The ISUSS approach is a particular approach that seeks to stimulate knowledge co-production and integration on the problem situation by involving practitioners and researcher in a transdisciplinary process. Using an exploratory methodology and involving in reflexive engagement with the participants, we provided preliminary insights on the use of the ISUSS approach with respect to enabling communication, encouraging social learning and developing shared understanding for consensus building in the context of environmental health in Dortmund. Similarly, we were able to 
map knowledge and perspectives of various participants on the problem situation in environmental health context in Dortmund. In doing so, various underlying drivers and causes for the detected inequalities in the area were identified jointly, including both constraints and potentials, as shown in Figures 5 and 6.

Various participatory methods and approaches have been designed with the aim of knowledge co-production and integration [28]. The ISUSS approach shares similar epistemologies with these approaches regarding enabling communication, encouraging social learning and developing shared understanding. Nonetheless, our approach differs from others in the following aspects. The approach is designed explicitly to support a transdisciplinary dialogue among and between practitioners and researchers. In doing so, it aims to enable confrontation and combination of the explicit knowledge with the tacit knowledge of participants actively in a dialogue. In particular, the ISUSS approach support two types of knowledge integration as discussed for transdisciplinary research processes [19,33]: integrating different modes of thought and integrating interests and worldviews from different stakeholders. A potential benefit of using the ISUSS approach is that it allows the participants to explore multiple indicators in various combinations, to switch between various scales and levels (neighborhood to city), and to integrate both spatial and non-spatial factors interactively.

Nevertheless, the approach entails two main challenges: completeness and comprehensiveness of indicators and proper tool-related facilitation. It was noted that, during the interactive mapping session, particularly while exploring existing spatial information, the discussion was somewhat constrained either by limited number of indicators or unavailability of small scaled data. Similarly, while proper facilitation is needed to ensure the quality of any participatory approach, the importance of tool related facilitation becomes particularly important in the ISUSS approach. The risk of participants being distracted while using the interactive maps was mitigated by the chauffeur who supported the participants to use the tool where needed. Likewise, the risk of meaningless scribbles on the rich picture as concerned by others [84] was mitigated in the ISUSS workshop by the facilitator who ensured that the participants describe the picture as they draw so that other participants understand the meaning associated to it. Therefore, skills of the facilitator and chauffeur in the ISUSS approach are essential to the process.

The ISUSS workshop in this study was conducted with six participants. Our intention was to construct a comprehensive workshop process and to provide initial information about the use of the ISUSS approach. This has led us to adopt exploratory methodology and to report insights on the use of the ISUSS approach rather than a controlled experimental settings with quantitative analysis like ANOVA-based design [85]. This is worth being explored in further application studies of the ISUSS approach.

We hardly touch upon the evaluation of the ISUSS approach based on its outputs-spatial knowledge map and rich picture-and their uptake in actual decision making process. The participants during the ISUSS workshop brought diverse knowledge and perspectives from various sectors on environmental health issues in Dortmund, but the small number of participants in this study has limited the representativeness of the spatial knowledge map and the rich picture generated. Nonetheless the participants represent a diverse group needed for a transdisciplinary approach [86]. In the Jufo-Salus public health and urban planning work together in an interdisciplinary manner and the stakeholder groups were selected systematically to represent relevant topics of environmental health in Dortmund. Due to the design of the Jufo-Salus research group neither citizens nor politicians have been involved. The knowledge and values of these stakeholders who have not participated in the ISUSS workshop might be different but equally relevant. Similarly, the ISUSS workshop with its interactive maps and rich picture allow reflecting on existing models of determinants of health [87], however, this is beyond the scope of this paper. Therefore, further empirical studies can shed light on the ISUSS approach based on the outputs and their actual use in decision process by extending the approach to various groups in real-world context. 
The ISUSS approach, as with other participatory methods, also depends on several other factors such as group dynamics, and the knowledge base of the participants on the topic. Having a group with contrasting norms, values and competing knowledge together with a constructive conflict among the group can improve understanding of a situation with new insights [88]. However, we found that the participants in the ISUSS workshop were partly like-minded. As such, the group appeared to have comparable norms, values and lack of challenging assumptions; at least they did not become obvious. This might have been caused by having the stakeholders who volunteer to participate in the research context of Jufo-Salus. Nonetheless, the participants brought various knowledge and perspectives about the problem situation. The ISUSS approach with a group of "different-minded" would have resulted into increased confrontation of contrasting and even competing knowledge claims, which would have enriched the discussion.

Transdisciplinary research practice requires to facilitate process of mutual learning between science and society, enable co-production and integration of knowledge from science and practice through co-leadership among all the relevant stakeholders [33]. In this regards, only getting stakeholders to participate is not enough to break hierarchical relationships as in the traditional form of knowledge production. In the ISUSS workshop, we noted that the participants remained active, stimulated and engaged throughout the workshop and the knowledge production evolved from a one-directional information provision or unidirectional knowledge transfer to interactive knowledge co-production. Visual artefacts used in the ISUSS in the form of interactive maps on the MapTable and rich picture offered a "dialogue space" and "shared language" to engage in a dialogue process. Moreover, the methods encouraged a "learning by doing" and "knowing-in-action" [89] attitude among the participants and enabled the stakeholders to be co-creators in the process of knowledge co-production and integration. Similarly, transforming the conditions that influence health requires broad-based collaborative partnerships among practitioners, researchers, and beneficiaries. In this sense, the approach has laid foundations for "transformative reflexivity" in transdisciplinary research as described by Kindon [90] (p. 264) "in which both researcher and researched reflect on their (mis)understandings and negotiated the meanings of information generated together" [28]. During the workshop, construction and negotiation of meaning became evident such as defining accessibility in terms of safety rather than in terms of distance by the participants before exploring the issues further.

We gained insights about the ISUSS approach both on a conceptual as well as on an operational level. The method is applicable for projects that deal with complex spatial problems and are required to include diverse knowledge and perspectives, both spatial and non-spatial, In the future the method might be applied within transdisciplinary processes as shared problem understanding and co-production of knowledge is a crucial point. In addition, with the ISUSS approach various frames can be brought to the fore and may increase the awareness among stakeholders and researcher that multiple frames or even competing claims exist. The ISUSS approach as presented here is designed for involving practitioners in early phase of problem understanding in transdisciplinary research practice. In the future, it is interesting to study its applicability to involve citizens with their knowledge and perspectives in the process or real-world decision problem. Nonetheless, the approach might require modifications in several aspects such as achieving representativeness of the group, combining knowledge maps from different groups together.

Acknowledgments: We would like to express our gratitude to Jufo-Salus (Junior Research Group “The City as healthy living environment independent of social inequalities"): Technical University Dortmund, Faculty of Spatial Planning, Department of Urban and Regional Planning, Dortmund, Germany (Sabine Baumgart, Andrea Rüdiger, Raphael Sieber, Lisa Waegerle); University of Bremen, Faculty of Human and Health Sciences, Institute of Public Health and Nursing Research, Department of Social Epidemiology, Bremen, Germany (Gabriele Bolte, Ursula Hemetek, Steffen Schüle); University of Applied Sciences Fulda, Faculty of Caring and Health, Public Health Institute, Department of Health Promotion, Fulda, Germany (Beate Blättner, Ursula Hemetek). We would also like to extend our gratitude to the reviewers of this paper. This research was supported by the foundation "Fritz und Hildegard Berg-Stiftung" within the "Stifterverband für die Deutsche Wissenschaft e.V.", Essen, Germany. The open access publication of the paper was partly funded by the Open Access Grant of the University of Twente. 
Author Contributions: Rehana Shrestha initiated the research, conceptualized the ISUSS approach, designed the workshop, carried out the role of chauffeur during the workshop, conducted the analysis and wrote the paper. Heike Koeckler participated in the workshop as a researcher and substantially commented on and contributed to the paper. Johannes Flacke facilitated the workshop as a process facilitator and commented on the paper substantially. Javier Martinez and Martin van Maarseveen contributed on the paper by providing comments.

Conflicts of Interest: The authors declare no conflict of interest.

\section{Appendix}

Table A1. List of Indicator Maps with the description.

\begin{tabular}{|c|c|c|}
\hline \multirow{2}{*}{ Factors } & Indicators & Description \\
\hline & Green and Water Areas & According to RVR Mapping \\
\hline \multirow{3}{*}{ Environmental factors } & $\begin{array}{l}\text { Noise level from industries; Noise level } \\
\text { from rail transport: railway, tram; Noise } \\
\text { level from road traffic }\end{array}$ & $24 \mathrm{~h}$ level in $\mathrm{dB}(\mathrm{A}), 2007$ \\
\hline & $\begin{array}{l}\text { Total Particulate Matter }\left(\mathrm{PM}_{10}\right) \text { and } \\
\text { from street; Total Nitrogen Dioxide } \\
\left(\mathrm{NO}_{2}\right) \text { and from street }\end{array}$ & $\begin{array}{l}\text { Annual average in } \mathrm{g} / \mathrm{m}^{3}, 2000-2012 \\
\text { modeled in } 2013\end{array}$ \\
\hline & Average Daily Traffic & Volume DTV in veh/24 h, 2007 \\
\hline \multirow{4}{*}{ Social factors } & Social benefits: SGB II & $\begin{array}{l}\text { Percentage of working age population } \\
\text { (15-65 years) receiving SGB II at statistical } \\
\text { sub-district, } 2012\end{array}$ \\
\hline & $\begin{array}{l}\text { Basic security in old age, disability, } \\
\text { assistance for livelihood share: SGB XII }\end{array}$ & $\begin{array}{l}\text { Percentage of basic security receiver per } \\
\text { statistical district } 2011\end{array}$ \\
\hline & $\begin{array}{l}\text { Children up to } 6 \text { years; Children and } \\
\text { adolescents ( }>6-14 \text { years) }\end{array}$ & $\begin{array}{l}\text { Percentage of children per statistical } \\
\text { district, } 2012\end{array}$ \\
\hline & People with migration background & $\begin{array}{l}\text { Percentage of people with a migration } \\
\text { background per statistical sub-district, } 2012\end{array}$ \\
\hline \multirow{5}{*}{ Other factors } & Administrative boundary & $\begin{array}{l}\text { Dortmund city districts (12), statistical } \\
\text { districts (62), statistical sub-districts (170) }\end{array}$ \\
\hline & Land use plan & Existing/planned land use zoning, 2004 \\
\hline & $\begin{array}{l}\text { Real land use: Commercial and industry } \\
\text { use, Residential and mixed use }\end{array}$ & According to RVR mapping \\
\hline & $\begin{array}{l}\text { Point locations: schools, kindergartens, } \\
\text { playgrounds, hospitals, nursing homes }\end{array}$ & According to RVR mapping, 2003-2008 \\
\hline & Power line distribution & In KV, 2004 \\
\hline
\end{tabular}

\section{References}

1. WHO. The Ottawa Charter for Health Promotion: First International Conference on Health Promotion, Ottawa, 21 November 1986; WHO: Geneva, Switzerland, 1986.

2. Hancock, T. The evolution, impact and significance of the health cities/healthy communities movement. J. Public Health Policy 1993, 14, 5-18. [CrossRef] [PubMed]

3. Stahl, T.; Wismar, M.; Ollila, E.; Lahtinen, E.; Leppo, K. Health in all Policies. Prospects and Potentials; Finnish Ministry of Social Affairs and Health: Helsinki, Finland, 2006.

4. Rudolph, L.; Caplan, J.; Ben-Moshe, K.; Dillon, L. Health in All Policies: A Guide for State and Local Governments; American Public Health Association and Public Health Institute: Washington, DC, USA, 2013.

5. Barton, H. Land use planning and health and well-being. Land Use Policy 2009, 26, 115-123. [CrossRef]

6. Corburn, J.; Bhatia, R. Health impact assessment in San Francisco: Incorporating the social determinants of health into environmental planning. J. Environ. Plan. Manag. 2007, 50, 323-341. [CrossRef]

7. Corburn, J. Confronting the challenges in reconnecting urban planning and public health. Am. J. Public Health 2004, 94, 541-546. [CrossRef] [PubMed]

8. Barton, H.; Grant, M. Urban planning for healthy cities. J. Urban Health 2013, 90, 129-141. [CrossRef] [PubMed] 
9. Marmot, M.; Friel, S.; Bell, R.; Houweling, T.A.; Taylor, S. Closing the gap in a generation: Health equity through action on the social determinants of health. Lancet 2008, 372, 1661-1669. [CrossRef]

10. Schulz, A.; Northridge, M.E. Social determinants of health: Implications for environmental health promotion. Health Educ. Behav. 2004, 31, 455-471. [CrossRef] [PubMed]

11. Abernethy, P. Bridging conceptual "silos": Bringing together health promotion and sustainability governance for practitioners at the landscape scale. Local Environ. 2014, 21, 451-475. [CrossRef]

12. Jackson, L.E. The relationship of urban design to human health and condition. Landsc. Urban Plan. 2003, 64, 191-200. [CrossRef]

13. Rosenfield, P.L. The potential of transdisciplinary research for sustaining and extending linkages between the health and social sciences. Soc. Sci. Med. 1992, 35, 1343-1357. [CrossRef]

14. Holmes, J.H.; Lehman, A.; Hade, E.; Ferketich, A.K.; Gehlert, S.; Rauscher, G.H.; Abrams, J.; Bird, C.E. Challenges for Multilevel Health Disparities Research in a Transdisciplinary Environment. Am. J. Prev. Med. 2008, 35, S182-S192. [CrossRef] [PubMed]

15. Khreis, H.; Warsow, K.M.; Verlinghieri, E.; Guzman, A.; Pellecuer, L.; Ferreira, A.; Jones, I.; Heinen, E.; Rojas-Rueda, D.; Mueller, N. The health impacts of traffic-related exposures in urban areas: Understanding real effects, underlying driving forces and co-producing future directions. J. Transp. Health 2016, 3, 249-267. [CrossRef]

16. Scholz, R.W. The Normative Dimension in Transdisciplinarity, Transition Management, and Transformation Sciences: New Roles of Science and Universities in Sustainable Transitioning. Sustainability 2017, 9, 991. [CrossRef]

17. Scholz, R.W.; Mieg, H.A.; Oswald, J.E. Transdisciplinarity in groundwater management-Towards mutual learning of science and society. Water Air Soil Pollut. 2000, 123, 477-487. [CrossRef]

18. Klein, J.T.; Grossenbacher-Mansuy, W.; Häberli, R.; Bill, A.; Scholz, R.W.; Welti, M. Transdisciplinarity: Joint Problem Solving among Science, Technology, and Society. An Effective Way for Managing Complexity; Birkhauser: Basel, Switzerland, 2001.

19. Scholz, R.W.; Roy, A.H.; Hellums, D.T. Sustainable Phosphorus Management: A Transdisciplinary Challenge. In Sustainable Phosphorus Management: A Global Transdisciplinary Roadmap; Scholz, R.W., Roy, A.H., Brand, F.S., Hellums, D.T., Ulrich, A.E., Eds.; Springer: Berlin, Germany, 2014; pp. 1-113.

20. Lawrence, R.J. Housing and health: From interdisciplinary principles to transdisciplinary research and practice. Futures 2004, 36, 487-502. [CrossRef]

21. Boylorn, R. Participants as co-researchers. In The SAGE Encyclopedia of Qualitative Research Methods; Given, L.M., Ed.; Sage: Los Angeles, CA, USA, 2008; pp. 600-602.

22. Scholz, R.W. Mutual learning as a basic principle of transdisciplinarity. In Transdisciplinarity: Joint Problem-Solving among Science, Technology and Society. Workbook II: Mutual Learning Sessions; Scholz, R.W., Häberli, R., Bill, A., Welti, M., Eds.; Haffman: Zurich, Switzerland, 2000; pp. 13-17.

23. Schulz, A.J.; Kannan, S.; Dvonch, J.T.; Israel, B.A.; Allen, A., III; James, S.A.; House, J.S.; Lepkowski, J. Social and physical environments and disparities in risk for cardiovascular disease: The healthy environments partnership conceptual model. Environ. Health Perspect. 2005, 113, 1817-1825. [CrossRef] [PubMed]

24. Northridge, M.E.; Sclar, E.D.; Biswas, M.P. Sorting out the connections between the built environment and health: A conceptual framework for navigating pathways and planning healthy cities. J. Urban Health 2003, 80, 556-568. [CrossRef] [PubMed]

25. Diez Roux, A.V.; Mair, C. Neighborhoods and health. Ann. N. Y. Acad. Sci. 2010, 1186, 125-145. [CrossRef] [PubMed]

26. Voigtländer, S.; Berger, U.; Razum, O. The impact of regional and neighbourhood deprivation on physical health in Germany: A multilevel study. BMC Public Health 2010, 10, 1-12. [CrossRef] [PubMed]

27. Fazey, I.; Evely, A.C.; Reed, M.S.; Stringer, L.C.; Kruijsen, J.; White, P.C.; Newsham, A.; Jin, L.; Cortazzi, M.; Phillipson, J. Knowledge exchange: A review and research agenda for environmental management. Environ. Conserv. 2013, 40, 19-36. [CrossRef]

28. Preller, B.; Affolderbach, J.; Schulz, C.; Fastenrath, S.; Braun, B. Interactive Knowledge Generation in Urban Green Building Transitions. Prof. Geogr. 2017, 69, 214-224. [CrossRef]

29. Andrienko, G.; Andrienko, N.; Jankowski, P.; Keim, D.; Kraak, M.J.; MacEachren, A.; Wrobel, S. Geovisual analytics for spatial decision support: Setting the research agenda. Int. J. Geogr. Inf. Sci. 2007, 21, 839-857. [CrossRef] 
30. Cadag, J.R.D.; Gaillard, J. Integrating knowledge and actions in disaster risk reduction: The contribution of participatory mapping. Area 2012, 44, 100-109. [CrossRef]

31. Dennis, S.F.; Gaulocher, S.; Carpiano, R.M.; Brown, D. Participatory photo mapping (PPM): Exploring an integrated method for health and place research with young people. Health Place 2009, 15, 466-473. [CrossRef] [PubMed]

32. Ackermann, F. Problem structuring methods 'in the Dock': Arguing the case for Soft OR. Eur. J. Oper. Res. 2012, 219, 652-658. [CrossRef]

33. Scholz, R.W.; Steiner, G. The real type and ideal type of transdisciplinary processes: Part I-Theoretical foundations. Sustain. Sci. 2015, 10, 527-544. [CrossRef]

34. Scholz, R.W.; Tietje, O. Embedded Case Study Methods: Integrating Quantitative and Qualitative Knowledge; Sage: Thousand Oaks, CA, USA, 2002.

35. Vilsmaier, U.; Engbers, M.; Luthardt, P.; Maas-Deipenbrock, R.M.; Wunderlich, S.; Scholz, R.W. Case-based mutual learning sessions: Knowledge integration and transfer in transdisciplinary processes. Sustain. Sci. 2015, 10, 563-580. [CrossRef]

36. Pfeffer, K.; Baud, I.; Denis, E.; Scott, D.; Sydenstricker-Neto, J. Participatory spatial knowledge management tools: Empowerment and upscaling or exclusion? Inf. Commun. Soci. 2013, 16, 258-285. [CrossRef]

37. Polanyi, M. The Tacit Dimension; Doubleday and Co.: Garden City, NY, USA, 1966.

38. Te Brömmelstroet, M.; Bertolini, L. Integrating land use and transport knowledge in strategy-making. Transportation 2010, 37, 85-104. [CrossRef]

39. Te Brómmelstroet, M.; Schrijnen, P.M. From planning support systems to mediated planning support: A structured dialogue to overcome the implementation gap. Environ. Plan. B 2010, 37, 3-20. [CrossRef]

40. Nonaka, I.; Takeuchi, H. The Knowledge-Creating Company: How Japanese Companies Create the Dynamics of Innovation: How Japanese Companies Create the Dynamics of Innovation; Oxford University Press: New York, NY, USA, 1995.

41. Mingers, J. Multimethodology. In Wiley Encyclopedia of Operations Research and Management Science; John Wiley \& Sons, Inc.: New York, NY, USA, 2010.

42. Franco, L.A.; Lord, E. Understanding multi-methodology: Evaluating the perceived impact of mixing methods for group budgetary decisions. Omega 2011, 39, 362-372. [CrossRef]

43. Voigtländer, S.; Mielck, A.; Razum, O. Die Bedeutung des kleinräumigen Kontexts für Gesundheit: Entwurf eines Erklärungsmodells. Das Gesundh. 2012, 74, 702-709. [CrossRef] [PubMed]

44. Andrienko, N.; Andrienko, G. The complexity challenge to creating useful and usable geovisualization tools. In Proceedings of the GIScience 4th International Conference on Geographic Information Science, Münster, Germany, 20-23 September 2006.

45. Bell, S.; Morse, S. Rich pictures: A means to explore the 'sustainable mind'? Sustain. Dev. 2013, $21,30-47$. [CrossRef]

46. Arciniegas, G. Map-Based Decision Support Tools for Collaborative Land Use Planning. Ph.D. Thesis, Vrije Universiteit Amsterdam, Amsterdam, The Netherlands, 2012.

47. Innes, J.E.; Booher, D.E. Collaborative policymaking: Governance through dialogue. In Deliberative Policy Analysis: Understanding Governance in the Network Society; Hajer, M.A., Wagenaar, H., Eds.; Cambridge University Press: Cambridge, UK, 2003; pp. 33-59.

48. Beukers, E.; Bertolini, L.; Te Brömmelstroet, M. Using cost benefit analysis as a learning process: Identifying interventions for improving communication and trust. Transp. Policy 2014, 31, 61-72. [CrossRef]

49. Hirokawa, R.Y.; Gouran, D.S. Facilitation of Group Communication a Critique of Prior Research and an Agenda for Future Research. Manag. Commun. Q. 1989, 3, 71-92. [CrossRef]

50. Pelzer, P.; Goodspeed, R.; te Brömmelstroet, M. Facilitating PSS Workshops: A Conceptual Framework and Findings from Interviews with Facilitators. In Planning Support Systems and Smart Cities. Lecture Notes in Geoinformation and Cartography; Geertman, S., Ferreira, J.J., Goodspeed, R., Stillwell, J., Eds.; Springer: Cham, Switzerland, 2015; pp. 355-369.

51. Niederman, F.; Beise, C.M.; Beranek, P.M. Issues and Concerns about Computer-Supported Meetings: The Facilitator's Perspective. MIS Q. 1996, 20, 1-22. [CrossRef]

52. Tee, M.Y.; Lee, S.S. Advancing understanding using Nonaka's model of knowledge creation and problem-based learning. Int. J. Comput. Support. Collab. Learn. 2013, 8, 313-331. [CrossRef] 
53. Rinner, C. Argumentation Mapping in Collaborative Spatial Decision Making. In Collaborative Geographic Information Systems; Balaram, S., Dragicevic, S., Eds.; Idea Group Publishing: Hershey, PA, USA, 2006; pp. 85-102.

54. Rémy, E.; Mougenot, C. Inventories and maps: Cognitive ways of framing the nature policies in Europe. J. Environ. Policy Plan. 2002, 4, 313-322. [CrossRef]

55. Tversky, B. Some Ways that Maps and Diagrams Communicate. In Spatial Cognition II: Integrating Abstract Theories, Empirical Studies, Formal Methods, and Practical Applications; Freska, C., Brauer, W., Habel, C., Wender, K.F., Eds.; Springer: Berlin/Heidelberg, Germany, 2000; pp. 72-79.

56. Healey, P. Planning Through Debate: The Communicative Turn in Planning Theory. In The Argumentative Turn in Policy Analysis and Planning; Fischer, F., Forester, J., Eds.; Duke University Press: Durham, NC, USA, 1993; pp. 233-253.

57. Fischer, F.; Forester, J. The Argumentative Turn in Policy Analysis and Planning; Duke University Press: Durham, NC, USA, 1993; p. 336.

58. Healey, P. Institutionalist analysis, communicative planning, and shaping places. J. Plan. Educ. Res. 1999, 19, 111-121. [CrossRef]

59. Innes, J.E. Information in communicative planning. J. Am. Plan. Assoc. 1998, 64, 52-63. [CrossRef]

60. Bandura, A. Social learning through imitation. In Nebraska Symposium on Motivation; Jones, M.R., Ed.; University of Nebraska Press: Lincoln, NB, USA, 1962; pp. 211-269.

61. Reed, M.; Evely, A.C.; Cundill, G.; Fazey, I.R.A.; Glass, J.; Laing, A.; Newig, J.; Parrish, B.; Prell, C.; Raymond, C. What is social learning? Ecol. Soc. 2010, 15, 1. [CrossRef]

62. Scholz, G.; Dewulf, A.; Pahl-Wostl, C. An analytical framework of social learning facilitated by participatory methods. Syst. Pract. Action Res. 2014, 27, 575-591. [CrossRef]

63. Goffman, E. Frame Analysis: An Essay on the Organization of Experience; North-eastern University Press: Boston, MA, USA, 1974.

64. Van Lieshout, M.; Dewulf, A.; Aarts, N.; Termeer, C. Do scale frames matter? Scale frame mismatches in the decision making process of a 'mega farm'in a small Dutch village. Ecol. Soc. 2011, 16, 38. [CrossRef]

65. Jones, N.; Ross, H.; Lynam, T.; Perez, P.; Leitch, A. Mental models: An interdisciplinary synthesis of theory and methods. Ecol. Soc. 2011, 16, 46. [CrossRef]

66. De Boer, J.; Wardekker, J.A.; Van der Sluijs, J.P. Frame-based guide to situated decision-making on climate change. Glob. Environ. Chang. 2010, 20, 502-510. [CrossRef]

67. Carton, L.J. Map Making and Map Use in a Multi-Actor Context: Spatial Visualizations and Frame Conflicts in Regional Policymaking in The Netherlands. Ph.D. Thesis, Delft University of Technology, Delft, The Netherlands, 2007.

68. Healey, P. Urban Complexity and Spatial Strategies: Towards a Relational Planning for Our Times; Routledge: London, UK, 2007.

69. Mulder, I.J. Understanding designers designing for understanding: Collaborative learning and shared understanding in video-based communication. Ph.D. Thesis, Telematica Instituut, Enschede, The Netherlands, 2004.

70. Kaner, S. Facilitator's Guide to Participatory Decision-Making; Jossey-Bass: San Francisco, CA, USA, 2014.

71. Jufo Salus. Junior Research Group: The City as Healthy Living Environment Independent of Social Inequalities. Available online: http://www.jufo-salus.de/cms/en/Welcome/index.html (accessed on 25 October 2017).

72. Shrestha, R.; Flacke, J.; Martinez, J.; Van Maarseveen, M. Environmental Health Related Socio-Spatial Inequalities: Identifying "Hotspots" of Environmental Burdens and Social Vulnerability. Int. J. Environ. Res. Public Health 2016, 13, 691. [CrossRef] [PubMed]

73. Flacke, J.; Schüle, S.A.; Köckler, H.; Bolte, G. Mapping Environmental Inequalities Relevant for Health for Informing Urban Planning Interventions-A Case Study in the City of Dortmund, Germany. Int. J. Environ. Res. Public Health 2016, 13, 711. [CrossRef] [PubMed]

74. Baumgart, S.; Blattner, B.; Bolte, G.; Flacke, J.; Kockler, H.; Rudiger, A. Gesunde Staedte fuer alle: Gemeinsame Strategien von Stadtplanung und Public Health. Planerin 2012, 5, 47-48.

75. Koeckler, H.; Blaettner, B.; Bolte, G.; Flacke, J.; Ruediger, A.; Baumgart, S. Gesundheitsfoerdernde Stadtentwicklung fuer alle: Gemeinsam den Bestand entwickeln. UMID 2014, 2, 23-29. 
76. Pihkala, S.; Karasti, H. Reflexive Engagement- Reflexive Orientation for Participatory Design. In Proceedings of the IADIS International Conference ICT, Society and Human Beings 2013, Prague, Czech Republic, 24-2 July 2013.

77. Pelzer, P.; Geertman, S. Planning support systems and interdisciplinary learning. Plan. Theory Pract. 2014, 15, 527-542. [CrossRef]

78. Whitehead, M. The concepts and principles of equity and health. Health Promot. Int. 1991, 6, $217-228$. [CrossRef]

79. Baden, B.M.; Noonan, D.S.; Turaga, R.M.R. Scales of justice: Is there a geographic bias in environmental equity analysis? J. Environ. Plan. Manag. 2007, 50, 163-185. [CrossRef]

80. Forester, J. The Deliberative Practitioner: Encouraging Participatory Planning Processes; MIT Press: Cambridge, MA, UK, 1999.

81. Hopkins, L.D.; Ramanathan, R.; Pallathucheril, V.G. Interface for a sketch-planning workbench. Comput. Environ. Urban Syst. 2004, 28, 653-666. [CrossRef]

82. Pelzer, P.; Geertman, S.; van der Heijden, R.; Rouwette, E. The added value of Planning Support Systems: A practitioner's perspective. Comput. Environ. Urban Syst. 2014, 48, 16-27. [CrossRef]

83. Goodspeed, R. Planning Support Systems for Spatial Planning through Social Learning. Ph.D. Thesis, Massachusetts Institute of Technology, Cambridge, MA, USA, 2013.

84. Berg, T.; Pooley, R. Rich pictures: Collaborative communication through icons. Syst. Pract. Action Res. 2013, 26, 361-376. [CrossRef]

85. Njoroge, R.; Birech, R.; Arusey, C.; Korir, M.; Mutisya, C.; Scholz, R.W. Transdisciplinary processes of developing, applying, and evaluating a method for improving smallholder farmers' access to (phosphorus) fertilizers: The SMAP method. Sustain. Sci. 2015, 10, 601-619. [CrossRef]

86. Scholz, R.W.; Le, Q.B. A novice's guide to transdisciplinarity. In Sustainable Phosphorus Management: A Global Transdisciplinary Roadmap; Scholz, R.W., Roy, A.H., Brand, F.S., Hellums, D.T., Ulrich, A.E., Eds.; Springer: Berlin, Germany, 2014; pp. 118-122.

87. Bolte, G.; Bunge, C.; Hornberg, C.; Köckler, H.; Mielck, A. Umweltgerechtigkeit durch Chancengleichheit bei Umwelt und Gesundheit. Eine Einführung in die Thematik und Zielsetzung dieses Buches. Umweltgerechtigkeit Chancengleichheit Umw. Gesundh. Konzepte Datenlage Handl. 2012, 1, 15-37.

88. Cuppen, E. Diversity and constructive conflict in stakeholder dialogue: Considerations for design and methods. Policy Sci. 2012, 45, 23-46. [CrossRef]

89. Schön, D.A. Educating the Reflective Practitioner; Jossey-Bass: San Francisco, CA, USA, 1987.

90. Kindon, S. Participatory action research. In Qualitative Research Methods in Human Geography; Hay, I., Ed.; Oxford University Press: Oxford, UK, 2010. 